\title{
Much ado about something: a response to "COVID-19: underpowered randomised trials, or no randomised trials?"
}

\author{
Noah A. Haber ${ }^{1 *}$ D, Sarah E. Wieten ${ }^{1}$, Emily R. Smith² and David Nunan ${ }^{3}$
}

\begin{abstract}
Non-pharmaceutical interventions (NPI) for infectious diseases such as COVID-19 are particularly challenging given the complexities of what is both practical and ethical to randomize. We are often faced with the difficult decision between having weak trials or not having a trial at all. In a recent article, Dr. Atle Fretheim argues that statistically underpowered studies are still valuable, particularly in conjunction with other similar studies in meta-analysis in the context of the DANMASK-19 trial, asking "Surely, some trial evidence must be better than no trial evidence?" However, informative trials are not always feasible, and feasible trials are not always informative. In some cases, even a well-conducted but weakly designed and/or underpowered trial such as DANMASK-19 may be uninformative or worse, both individually and in a body of literature. Meta-analysis, for example, can only resolve issues of statistical power if there is a reasonable expectation of compatible well-designed trials. Uninformative designs may also invite misinformation. Here, we make the case that-when considering informativeness, ethics, and opportunity costs in addition to statistical power- "nothing" is often the better choice.
\end{abstract}

Keywords: Non-pharmaceutical interventions, Masks, Ethics, DANMASK-19, Statistical power

\section{Background}

In a recent commentary "COVID-19: underpowered randomised trials, or no randomised trials," Dr. Fretheim asks that "Surely, some trial evidence must be better than no trial evidence?" [1] when faced with the common decision of whether to conduct an underpowered trial or no trial at all. The commentary uses the example of DANMASK-19 $[2,3]$ trial to suggest that for public health and non-pharmaceutical interventions (NPIs) where we rarely have large, well-powered trials upon which to base decisions-well-conducted but underpowered trials can both demonstrate the feasibility of larger

This comment refers to the article available at https://doi.org/10.1186/ s13063-021-05209-5.

* Correspondence: noahhaber@stanford.edu

${ }^{1}$ Meta-Research Innovation Center at Stanford (METRICS), Stanford University, 1265 Welch Rd Palo Alto, Stanford, CA 94305, USA

Full list of author information is available at the end of the article trials and contribute toward a body of literature that can help reduce uncertainty. We agree that we must often face difficult choices when well-powered, well-designed, and well-conducted trials are not available. However, it is not a given that all trials contribute meaningfully toward reducing uncertainty or informing some hypothetical decision(s), either individually or collectively as part of the body of evidence. Uninformative trials-such as we argue is the case for DANMASK-19-can have harms [4]. Here, we make the case that when considering informativeness, ethics, and opportunity costs in addition to statistical power, "nothing" is often the better choice.

(c) The Author(s). 2021, corrected publication 2021. Open Access This article is licensed under a Creative Commons Attribution 4.0 International License, which permits use, sharing, adaptation, distribution and reproduction in any medium or format, as long as you give appropriate credit to the original author(s) and the source, provide a link to the Creative Commons licence, and indicate if changes were made. The images or other third party material in this article are included in the article's Creative Commons licence, unless indicated otherwise in a credit line to the material. If material is not included in the article's Creative Commons licence and your intended use is not permitted by statutory regulation or exceeds the permitted use, you will need to obtain permission directly from the copyright holder. To view a copy of this licence, visit http://creativecommons.org/ licenses/by/4.0/. The Creative Commons Public Domain Dedication waiver (http://creativecommons.org/publicdomain/zero/1. 0/) applies to the data made available in this article, unless otherwise stated in a credit line to the data. 


\section{Main text}

Implementing a well-designed trial for NPIs requires facing a different set of challenges compared to pharmaceutical interventions. For example, policy interventions require that the unit of randomization be government units and institutions rather than individuals. To do such a trial requires large numbers of observable units to comply with the policy orders of an external research organization and likely requires vast social, political, and logistical coordination. While the recently released early results of a 300,000 person, 600 village cluster RCT on the impact mask-related interventions for COVID-19 in Bangladesh $[5,6]$ demonstrates that such trials may be feasible, it also demonstrates the complex combination of strong design, social buy-in, resources, infrastructure, and circumstances required to achieve it. Compliance-both at the intervention and/or individual level-is a key component for NPIs and often requires behavioral elements, like distancing and mask usage, but is notoriously difficult to ensure or measure. NPIs are also extremely heterogeneous and conditional on the specific settings in which they take place, posing difficulties for generalizability. Even stepped-wedge designs, often used for intervention roll-outs over time, are challenging when the outcome is an infectious disease [7] such as COVID-19; infectious disease takes time to spread through a population, outcomes may not manifest for weeks or months, and outcomes are highly subject to spillovers, population conditions, and complex disease dynamics over time. These issues and others mean that NPIs are particularly challenging to study with randomization or any other impact evaluation design.

Beyond statistical power, what is feasible to randomize and measure is often not informative for what we want to know. The DANMASK-19 authors defend their study as being a pragmatic trial [8], but having pragmatic limitations is not the same as designing a pragmatic trial [9]. It was not feasible to randomize mask wearing in the DANMASK-19 trial, nor was it feasible to measure community spread. In the DANMASK-19 trial, the main intervention was messages about mask wearing; it only measured infections for the employees enrolled in the trial rather than transmission to others (source controlarguably a more relevant concern for policy recommendations) and did not meaningfully measure the impact of messages on mask-wearing behavior. ${ }^{1}$ As a trial about

\footnotetext{
${ }^{1}$ The DANMASK-19 trial included a single question on compliance which was asked only to the messages arm, and the question asked included only the three options: as recommended, predominantly as recommended, and not as recommended, with no option between predominantly as recommended complying and not as recommended. This also did not ask about mask wearing behavior itself, just selfreported protocol compliance. Further, no question was asked about the mask-wearing behaviors of the non-messages arm. As a result, we do not know the differential mask-wearing behavior between the arms.
}

the impact of messages, this trial was underpowered and poorly measured at the outset of its design. As a trial about the impact of mask wearing, it risks being severely biased toward the null due to compliance and testing [10]. Neither of the above interpretations meaningfully inform any decision.

While meta-analysis can often resolve issues of power as Dr. Fretheim notes, that is only true when there is a reasonable expectation that enough sufficiently compatible, well-designed, and well-executed trials will come into existence to collectively power one or more metaanalyses. While we do not need to be held back by arbitrary power thresholds [11], we must consider how much information our trials actually provide and at what expense [12]. That is a difficult value proposition for NPI trials, which often must deal with high degree of heterogeneity in the population, intervention, comparison group, and outcomes. No two "stay-at-home" mandates were the same, nor would we expect trials of them to be. At the very least, this heterogeneity increases meta-analysis sample sizes. At worst, it can render studies incompatible for comparison. In the case of DANM ASK-19, it is difficult to imagine circumstances aligning to allow for many trials of comparable design for metaanalysis be feasible. Uncoordinated and underpowered trials lead to research waste [13]. Meta-analysis relies critically on the design strengths and weaknesses of its constituent parts; a meta-analysis of poorly designed studies is a poorly designed meta-analysis.

Note that our argument does not rely on the use of nullhypothesis significance testing, whether through p-values or other metrics, nor do we consider it the most relevant metric. Statistical power is important under any decisionmaking paradigm, whether value for information-based frameworks, confidence interval decision thresholds, or others. The most important component of the evidentiary strength of a given study is in its design, rather than posthoc measurements of uncertainty that result from its execution. Some of us expressed our concerns about DANM ASK-19's design issues before any results were released or available, but unfortunately after the trial had already been completed. Notably, our concern applies to the decision for whether to carry out a study a priori at the planning stages, not for publication considerations. Once a trial is conducted, in general it should be published in such a way to make its limitations well understood, regardless of the results.

If it is questionable that either individually or collectively, a hypothetical NPI trial would be informative, then we also must consider the ethical considerations for the trial participants. Why enroll participants, risk personal data, etc. for a trial that has little hope of being usefully informative and, therefore, little hope of providing social value? [14]. For NPIs, that is further complicated by the fact that individuals often cannot 
practically consent for group-level interventions and individual consent requirements can be waived only in some contexts [15]. Sorting out which consent requirements apply for a particular NPI study, even when well designed and adequately powered, can be complex. Beyond the participants, we must also consider the ethical ramifications to researchers, policy-makers, consumers, and those who might be impacted by decisions made due to poorly designed or underpowered research.

Randomized trials typically require large investments in coordination, funding, time, and other resources. Underpowered and poorly designed trials come without much hope of useful information in exchange for the expense. These are opportunity costs; we must also consider the value that could be achieved investing those resources elsewhere, including in different areas of research or in non-research investments. Resources for research are often not zero-sum, but they are always limited.

Underpowered and poorly designed trials are often worse than uninformative; they can be actively misinformative. Understanding why the DANMASK-19 trial was not suitably designed or powered to be informative for any actionable question requires a deep understanding of issues around statistical power, null hypothesis significance testing, and study design, as well as the time to dive into it. Without that, the DANMASK-19 trial invites misinterpretation, particularly with regard to fallacious interpretation of statistical insignificance. An uninformative trial that also invites misinterpretation can only have negative information gain, leading to misinformation for policy makers, researchers, journalists, and research consumers. Dr. Fretheim provides an example with misinformative headlines from the Daily Mail, but the same issues are common among researchers. For example, Oraby et al., [16] inaccurately claim that "the Danish mask study showed the overall effects from mask wearing and social distancing were modest." This may be further exacerbated by a misheld belief that randomized trials are automatically "gold standard" evidence, leading to unjustified benefit of the doubt on their usefulness and uncritical adoption of their findings.

\section{Conclusions}

"Nothing" is often the best alternative use of those resources and "something" often means a potentially costly endeavor which may have little (or negative) contribution toward informed decisions. While Dr. Fretheim argues that DANMASK-19 demonstrates that trials involving NPIs are feasible, it did not demonstrate that what is feasible is informative; uninformative trials can increase uncertainty rather than resolve it. The issues with DANMASK-19 are shared with running randomized trials for many NPIs. Because randomized trials are considered by many as unquestionably robust evidence, uninformative trials for complex and important public health interventions are particularly at risk of causing harm. However, that strong trial designs for important questions are often infeasible does not mean we should accept trials of lower quality, nor that other impact evaluation study designs can adequately fill the gap [17]. There simply may not be a feasible trial that can give us the reliable and direct answers we seek. A too-weak "something" can actively obscure the extent of the true uncertainty and impede alternative decision-strategies, such as hedging bets and leaning more on theoretical grounds. In those circumstances it may be preferable to reconsider whether a trial might be of sufficient value to be worth the costs. Sometimes, an honest and frank "nothing" may be the best option we have.

\section{Abbreviations}

COVID-19: Coronavirus disease 2019; NPI: Non-pharmaceutical interventions

\section{Acknowledgements}

We would like to thank Dr. Atle Fretheim for his excellent discussion on this complex topic and Dr. Steven Goodman for helpful suggestions during the editing process.

\section{Authors' contributions}

All authors contributed to the writing and editing of this manuscript. The author(s) read and approved the final manuscript.

Funding

No funding was provided specifically for the writing of this manuscript.

Availability of data and materials

Not applicable

\section{Declarations}

Ethics approval and consent to participate

Not applicable

Consent for publication

Not applicable

\section{Competing interests}

The authors have no competing interests to declare.

\section{Author details}

${ }^{1}$ Meta-Research Innovation Center at Stanford (METRICS), Stanford University, 1265 Welch Rd Palo Alto, Stanford, CA 94305, USA. ²Department of Global Health, Milken Institute School of Public Health, George Washington University, 950 New Hampshire Avenue, Washington, DC 20052, USA. ${ }^{3}$ Centre for Evidence Based Medicine, University of Oxford, Radcliffe Primary Care Building, Radcliffe Observatory Quarter, Woodstock Road, Oxford OX2 6GG, UK.

Received: 25 May 2021 Accepted: 19 October 2021

Published online: 07 November 2021

References

1. Fretheim A. COVID-19: underpowered randomised trials, or no randomised trials? Trials. 2021 Dec;22(1):234. https://doi.org/10.1186/s13063-021-05209-5.

2. Bundgaard $H$, Bundgaard JS, Raaschou-Pedersen DET, Mariager AF, Schytte $\mathrm{N}$, von Buchwald $\mathrm{C}$, et al. Face masks for the prevention of COVID-19 rationale and design of the randomised controlled trial DANMASK-19. Dan Med J. 2020 Aug;18:67(9).

3. Bundgaard H, Bundgaard JS, Raaschou-Pedersen DET, von Buchwald C, Todsen T, Norsk JB, et al. Effectiveness of adding a mask recommendation to other public health measures to prevent SARS-CoV-2 infection in danish 
mask wearers: a randomized controlled trial. Ann Intern Med. 2021 Mar; 174(3):335-43. https://doi.org/10.7326/M20-6817.

4. Zarin DA, Goodman SN, Kimmelman J. Harms from uninformative clinical trials. JAMA. 2019 Sep 3;322(9):813-4. https://doi.org/10.1001/ja ma.2019.9892

5. Abaluck J, Kwong L, Styczynski A, Haque A, Kabir MdA, Bates-Jefferys E, et al. Normalizing community mask-wearing: a cluster randomized trial in Bangladesh [Internet]. Cambridge, MA: National Bureau of Economic Research; 2021 Apr [cited 2021 May 4] p. w28734. Report No.: w28734 Available from: http://www.nber.org/papers/w28734.pdf

6. Abaluck J, Kwong L, Styczynski A, Haque A, Kabir MdA, Bates-Jefferys E, et al. The impact of community masking on COVID-19: a cluster-randomized trial in Bangladesh [Internet]. Innovations for Poverty Action; 2021 Sep [cited 2021 Sep 1]. Available from: https://www.poverty-action.org/publication/ impact-community-masking-covid-19-cluster-randomized-trial-bangladesh

7. Kennedy-Shaffer L, Lipsitch M. Statistical properties of stepped wedge cluster-randomized trials in infectious disease outbreaks. Am J Epidemiol. 2020 Nov 1;189(11):1324-32. https://doi.org/10.1093/aje/kwaa141.

8. Bundgaard $\mathrm{H}$, Bundgaard JS, Benfield T, Torp-Pedersen C, Ullum H, Iversen K. Response to letter of concern regarding "Reduction in COVID-19 infection using surgical facial masks outside the healthcare system". Dan Med J. 2020 Nov:11:67(12).

9. Welsing PM, Oude Rengerink K, Collier S, Eckert L, van Smeden M, Ciaglia A, et al. Series: Pragmatic trials and real world evidence: Paper 6. Outcome measures in the real world. J Clin Epidemiol. 2017 Oct;90:99-107. https:// doi.org/10.1016/j.jclinepi.2016.12.022.

10. Haber NA, Wieten SE, Smith ER. Letter of concern regarding "Reduction in COVID-19 infection using surgical facial masks outside the healthcare system". Dan Med J. 2020 Nov 11;67(12).

11. Bland JM. The tyranny of power: is there a better way to calculate sample size? BMJ. 2009 Oct 6;339(oct06 3):b3985-b3985.

12. Kunst N, Wilson ECF, Glynn D, Alarid-Escudero F, Baio G, Brennan A, et al. Computing the expected value of sample information efficiently: practical guidance and recommendations for four model-based methods. Value Health. 2020 Jun;23(6):734-42. https://doi.org/10.1016/j.jval.2020.02.010.

13. Glasziou PP, Sanders S, Hoffmann T. Waste in COVID-19 research. BMJ. 2020 May 12;369:m1847.

14. Wenner DM. The social value requirement in research: from the transactional to the basic structure model of stakeholder obligations. Hastings Cent Rep. 2018 Nov;48(6):25-32. https://doi.org/10.1002/hast.934.

15. McRae AD, Weijer C, Binik A, Grimshaw JM, Boruch R, Brehaut JC, et al. When is informed consent required in cluster randomized trials in health research? Trials. 2011 Dec;12(1):202. https://doi.org/10.1186/17456215-12-202.

16. Oraby T, Tyshenko MG, Maldonado JC, Vatcheva K, Elsaadany S, Alali WQ, et al. Modeling the effect of lockdown timing as a COVID-19 control measure in countries with differing social contacts. Sci Rep. 2021;11(1):3354. https:// doi.org/10.1038/s41598-021-82873-2.

17. Haber NA, Clarke-Deelder E, Feller A, Smith ER, Salomon J, MacCormackGelles B, et al. Problems with Evidence Assessment in COVID-19 Health Policy Impact Evaluation (PEACHPIE): a systematic review of evidence strength [Internet]. Health Policy; 2021 Jan [cited 2021 Feb 23]. Available from: http://medrxiv.org/lookup/doi/10.1101/2021.01.21.21250243

\section{Publisher's Note}

Springer Nature remains neutral with regard to jurisdictional claims in published maps and institutional affiliations.

Ready to submit your research? Choose BMC and benefit from:
- fast, convenient online submission
- thorough peer review by experienced researchers in your field
- rapid publication on acceptance
- support for research data, including large and complex data types
- gold Open Access which fosters wider collaboration and increased citations
- maximum visibility for your research: over 100M website views per year
At BMC, research is always in progress.
Learn more biomedcentral.com/submissions

